\title{
Research on the Problems Faced by LGBTQ University Students in China
}

\author{
Xingru Qu \\ Applied English in Xi'an Jiaotong Liverpool University,Suzhou, Jiangsu Province, 215000, China \\ Corresponding author.Email: gaoming@cas-harbour.org
}

\begin{abstract}
Sexual minorities refer to groups that are different from the majority of people in society in terms of sexual orientation, gender identity, sexual identity or sexual behavior, which is what we often call LGBTQ groups. 2021 is the 24th year of decriminalization of homosexuality and the 20th year of decriminalization of homosexuality. Networking has also initially exposed homosexuality into the public. Besides, homosexuals are less and less likely to deliberately hide their sexual orientation. At the same time, being exposed to the public will also bring pressure to them. This article uses interviews to discuss with seven college students about their life experiences at the university, focusing on the problems faced by the LGBTQ group of college students in China. Although the university is considered to have a more relaxed and open environment, there are still quite a few LGBTQ students in the university who will feel the strange vision from the teacher or the surrounding students, and at the same time they have to face the depression brought by the traditional atmosphere in the family and bears the stereotype of them in the society as well. Finally, this article combines the social and cultural background of China, and puts forward suggestions on the problems they face in these three environments. It come to the conclusion that different campus environments, family environments and social atmospheres bring LGBT groups different experiences and feelings, leading to their differences on some issues. These groups are all optimistic for the future.
\end{abstract}

Keywords: LGBTQ university students, difficulties, sexual prejudice, school orgnizations, school policy

\section{INTRODUCTION}

In the modern history of China, college students played an important role in raising social awareness and promoting social development. The current generation of college students has undergone tremendous social, economic, cultural and political changes in China [6]. As a young force, the LGBTQ group's perception of themselves is also changing among college students, what they feel, and what they What they want to express is vital to their future development. This article explores the problems they face from the school, social and family atmospheres as well as their expectations of the school. This research has a certain meaning for the establishment of prejudice-eliminating courses and teacher training in universities.

\section{LITERATURE REVIEW}

\subsection{Previous research on LGBTQ groups in schools}

From previous research on LGBTQ students in schools, the author has drawn several related topics: Firstly, previous research proved that students studying in schools with supportive minority organizations will feel more comfortable and more comfortable in school. Safety and mental health will be higher $[5,7,8]$. These organizations allow students to express their demands reasonably and bravely, and fight for equal rights for themselves. Secondly, as far as Hong Kong is concerned, at the institutional level, school policies, strengthened heterosexual attitudes, and imperfect curricula can reflect the school's sexual prejudice [2]. LGBTQ students lack the support of teachers. The sex education curriculum set up in China also lacks equal rights and anti-discrimination themes [3], which indirectly leads to the psychological problems of LGBTQ students. 


\subsection{Sexual prejudice in different cultural contexts}

The cultural background differences of different countries and even different regions will also create different sexual prejudices. Taking Hong Kong, China as an example, after more than 100 years of British colonial rule in Hong Kong, the influence of Christianity became more and more profound. Various forms of missionary work adopted. School curricula and education policies developed and played a very important role. For example, nearly half of public schools in Hong Kong are affiliated to religions. The principal has the right to decide whether or not to implement sex education courses in schools, which is based on religion. Because of the strong opposition from religious organizations, the rights of LGBTQ students cannot be guaranteed in schools. They will feel strong anxiety in schools with such religious backgrounds. For another, according to Christian values [2], taking mainland China as an example, traditional concepts will still be reflected in modern society. For example, in Confucianism, there are three unfilial behaviors, and the most unfilial behavior is the absence of offspring [2]. In Western countries, economically developed industrialized countries generally have a higher tolerance for LGBTQ people and more tolerant social policies [6], which is also consistent with the result of another study: the higher the level of economic development, the higher the level of economic development. There is less discrimination [9], and compared with East Asian countries, European and American countries conducted research on the academic experience of students from sexual minorities from the 1990s, while Asian countries started Research related issues and phenomena [2].

\subsection{Sexual prejudice and support from school organizations and teachers}

In addition to discrimination from parents and classmates, the information that teachers publicly disseminate in the school also has a great impact on the physical and mental health of LGBTQ students. For example, teachers' dissemination of information about sexual prejudice based on their personal beliefs will make LGBTQ students feel uncomfortable [2], which will immediately affect students' physical, social, and academic achievements [1]. The American Psychological Association proposed in 2009 that teachers' anti-discrimination sex education training courses should include information about The topic of gender diversity. In addition, some studies have put forward suggestions that the impact of local cultural and religious factors on students and teachers should be fully considered when carrying out relevant training projects. At the same time, sexual minorities among adolescents have a high probability of negative results, including drug abuse, deteriorating school performance, suicidal tendencies, etc. [4]. Psychological counseling is crucial for them when extreme situations occur. Important, Kwok and $\mathrm{Wu}$ suggested that psychological practitioners need to conduct mandatory anti-bullying training, include gender diversity issues in training courses, and prohibit the use of homophobic language among students [4].

\section{RESEARCH}

Considering the environment of college students, the questions of this study are as follows: 1) Does your university have a clear system for LGBTQ groups, such as supporting some of your activities or expressly prohibiting some activities such as tolerance/intolerance? What impact does the environment have on you? Such as your performance in school, and whether you intentionally conceal your sexual orientation? 2) Have the teachers in the school expressed support for or against sexual minorities in class or outside of class? What about the classmates and friends around you? 3) What is the atmosphere in your family? (Relatively open and relaxed or traditional?) Have you ever talked to your parents about your orientation or this aspect? What kind of feedback your parents give you? 4) Have you ever been treated unequally at work or outside of school (including on social media) and how did you do it? Have you ever changed your opinion because of outside voices? 5) Do you think that in Chinese universities, schools and teachers should protect sexual minorities? How to do it (For example, do you need clear regulations, or ambiguous?)? why? Could you please give some other suggestions?

This article uses semi-structured interviews, interviewing six students from different universities in three different regions.Three of them are from Sino-foreign joint universities, two are from the police school, and the other is from domestic university. The six students are all Chinese girls, have no religious beliefs, and have not came out to their parents, but have different degrees of coming out between school and friends. Three of them participated in the anti-bullying and anti-prejudice associations spontaneously organized by the school's middle school students to support equal rights and sexual minorities, and one had participated in an online forum for sexual minorities.

\section{RESULTS}

\subsection{School tolerance differences and impact}

In the research, the two girls in the police academy clearly felt that the school's attitude towards LGBTQ groups was biased against. Ye is one of the girls from the police academy. Here are her feelings and experiences: 
"Our school is regarded as a special institution. The basic attitude is to avoid talking. I do not think it can be regarded as a lack of attitude. Sexual orientation is more like something that cannot be stated on the surface. As long as it is brought up, it is basically opposed to it. It is similar to a previous press conference in the Civil Code. A Taiwan reporter asked why gay marriage was not passed. The answer is that there are not so many countries that have a gay marriage bill. Everyone does not say that as for students, we are more of a sense of powerlessness. We have no channels or courage to fight for our own rights and interests with the school and the society, and we do not even know what rights we want to fight for, so I admire those People who can organize LGBTQ activities on or off campus have the courage and courage."

In addition to the overall atmosphere of the school, some prejudiced messages conveyed by the teacher in the classroom also made her feel uncomfortable.

"There was a course called criminal psychology before the school. When the chapter on perversion, there were transvestites and homosexuality, including homosexuality, a high-risk group of AIDS, etc. The argument that has been outdated and overturned a long time ago, let us not say whether this tutorial has not been updated for a long time, but this also reflects the current society's ignorance of LGBT groups, and even the phenomenon of prejudice that teachers still use These prejudices are used to teach students. When talking about LGBT in class, you can often hear obvious laughter. Although I do not know what the meaning of their laughter is, I cannot speculate maliciously, but this is obviously strange. The reaction still made me feel that the tolerance of this society to this group is not as high as we thought."

Another girl from a domestic university, Zhou, has also experienced teachers publicly expressing different opinions in class.

"Some teachers in the school openly opposed it in class, and some supported it in class. The opposed teacher regarded sexual minorities as an abnormal group, and even the normal friendship between two women was misunderstood as "unnormal" in her words. The supporting teacher is a professor of law school, he discussed the legalization of gay marriage in an elective course."

Traditional family atmosphere is that parents and elders all express their expectations of marriage and children. The family atmosphere of the six girls is more traditional. When talking about homosexuality, they choose to avoid or remain silent. The following is Zhou's experience:
"The family atmosphere of the six girls is more traditional. When talking about homosexuality, they choose to avoid or remain silent. The following is Zhou's experience: "The family atmosphere is more traditional, but my parents have always respected my choice. I have not talked to my parents about my own orientation. I have tried my mother's attitude towards homosexuality. She said that this is not protected by law in China."

When the author asked how you would reply your family when they asked you about future marriage and childbirth, this is Ye's answer:

"Because I do not have a job or financial resources, I am slowly talking to them, and then test their attitude, and then they also said that it is about marriage, and I will give them a clear answer now that I do not plan to do so in the future. Get married, do not plan to have children, let them accept this one first, and then slowly transition. Parents' thoughts are more that if you are not married or have children, your happiness is not guaranteed, or that your future life in old age is not guaranteed, so they will feel uneasy, but if they can accept that there is no guarantee. If there is no legitimate children, then the issue of sexual orientation will be acceptable."

\subsection{Prejudice or support felt in society}

Zhao is now working as an intern in a company. She is one of the few people who feel the clear anti-discrimination regulations in society.

"In terms of my current job, the rules and regulations of our work clearly state that we cannot discriminate against sexual orientation, sexual orientation, and gender identity. These are all violations of the company's rules and regulations. Including my colleagues, they also talk about these issues very openly. I also came out of the closet to a few colleagues, and they were all very open minded."

\subsection{Their expectations of the school system}

When the author asked, do you think the school needs to set up some protection systems or organizations for sexual minorities? However, the author got different answers. Zhou thinks it is necessary to set up a system:.

"I think a clear system is needed to protect sexual minorities at this stage, because the fewer gender taboos, the more open and free human potential and life can be. On the contrary, the deeper the stereotype of gender and the more social repression, it will create infinite alienation, distortion and even tragedy. There is no shortage of young people from sexual minorities who have different degrees of psychological problems under the wrong guidance of the social environment. The protection of schools is 
an important factor on the road to equal rights, but it is a long way to go in terms of the permanent closure of the public accounts of the minorities in major colleges and universities some time ago."

"I think it is very important to hold relevant lectures and regular LGBTQ-related activities in Chinese universities to make more people aware of the normal existence of sexual minorities and to protect sexual minorities through education."

However, Zhao has different opinions.

"I do not think there is a need for clear rules and regulations to allow schools to protect sexual minorities. There is no need to treat them as a very special existence, as long as they are treated normally. If there is a clear stipulation, will it be that people who already hate this group will say why these people have to engage in special things. This kind of system is likely to arouse their resentment even more and play a counterproductive role."

\section{DISCUSSION}

Although they face different degrees of discrimination and prejudice, they still have a very optimistic attitude towards the acceptance of the future society. Ye says

"It is very difficult to change the concept of a group. I think it is better to wait for the renewal of this society than to let those middle-aged and elderly groups change their ideas and accept us. But now I am more optimistic that our age will basically understand and tolerate this When we become the "universal masses" of the society, sexual minorities may be protected by law"

A very interesting part of the interview process is that the three Chinese-foreign joint university students thought that sexual minorities should not be specialised in the question of whether the school should protect sexual minorities, and they hope that the school will do the same. The good society treats them like normal people; the other two girls think that system protection is necessary. Taking into account the different backgrounds of the interviewees, the schools of the three girls all have organizations that support equal rights for sexual minorities, and the school will not hold any objections, and there have been no incidents of bullying. There is no relevant organization in the school, and the teacher even publicly disseminates some prejudiced information in the classroom. Related research has shown that students who study in schools that support affirmative organizations are more likely to feel safe in school [2]. Hence, the three girls think they do not need to be protected because they already feel safe enough in school.

\section{CONCLUSION}

Through interviews with six LGBTQ college students, this article studies the status quo of the neutral minority group of college students in China. The study found that different campus environments, family environments and social atmospheres bring them different experiences and feelings, leading to their differences on some issues, but for the future they all have an optimistic attitude. For example, it can be seen from the interview that Ye's school does not have a school community that supports equal rights, so she is in favor of establishing a protection mechanism for sexual minorities in school. At the same time, she is influenced by teachers around her. Although she lives in a relatively open society, she still thinks that there are not many people around her who understand her. Zhao, who is a member of the anti-discrimination and pro-equality group at her school, does not agree with the establishment of a protective policy at her school because she does not want sexual minorities to be treated differently, and she believes that teachers and friends around her are understanding and do not treat her with prejudice. This research may help universities to develop anti-discrimination and pro-equality activities or curricula, and to increase this in teacher training.

\section{REFERENCES}

[1] C. Wei \& W. Liu. Coming out in Mainland China: A national survey of LGBTQ students, Journal of LGBT Youth, 2019, 16(2): 192-219.

[2] D.K. Kwok. Training educators to support sexual minority students: views of Chinese teachers, Sex Education, 2019, 19(3): 346-360.

[3] D.K. Kwok, and M. W. Lee. Contesting School Heterosexism: Rights-Based Sexuality

Education for LGBQ Students. In: K.J. Kennedy and J.C.K. Lee (eds.). Routledge Handbook on Schools and Schooling in Asia. 2018: 872-879.

[4] D.K. Kwok \& J. Wu. Chinese attitudes towards sexual minorities in Hong Kong: Implications for mental health, International Review of Psychiatry, 2015, 27(5): 444-454.

[5] N.C. Heck, L.M. Lindquist, B.T. Stewart, C. Brennan, and B.N. Cochran. To Join or Not to Join: Gay-Straight Student Alliances and the High School Experiences of Lesbian, Gay, Bisexual, and Transgender Youths. Journal of Gay \& Lesbian Social Services: the Quarterly Journal of Community \& Clinical Practice, 2013, 25(1): 77101.

[6] K. Lin, D. Button, M. Su, and S. Chen. Chinese College Students' Attitudes Toward 
Homosexuality: Exploring the Effects of Traditional Culture and Modernizing Factors. Sexuality Research and Social Policy, 2016, 13(2): 158-172.

[7] J.G. Kosciw, E.A. Greytak, N.A. Palmer, and M.J. Boesen. The 2013 National School Climate Survey: The Experiences of Lesbian, Gay, Bisexual and Transgender Youth in Our Nation's Schools. NY: Gay, Lesbian and Straight Education Network (GLSEN). 2014.

[8] P.V. Poteat, S.T. Russell, and A. Dewaele. Sexual Health Risk Behavior Disparities among Male and Female Adolescents Using Identity and Behavior Indicators of Sexual Orientation. Archives of Sexual Behavior, 2017(12): 1-11.

[9] Wang et al. BMC Public Health, 2020(20): 669. 